\title{
Monocyte expression of tissue factor and adhesion molecules: the link with accelerated coronary artery disease in patients with chronic renal failure
}

\author{
N M Al-Saady, E W Leatham, S Gupta, J T C Kwan, J B Eastwood, C A Seymour
}

\begin{abstract}
Objective-To investigate the expression of monocyte tissue factor (MTF) and adhesion molecules in patients with chronic renal failure (CRF) and to look for any correlation with thrombin generation and $L p(a)$ lipoprotein.

Design-A study of MTF expression and adhesion molecules, prothrombin fragments 1+2 (PTf1+2), an index of thrombin generation, and lipoproteins in patients with CRF and in normal control subjects. Background-Patients with end stage renal failure have an increased risk of coronary artery disease despite advances in therapy. Stimulated monocytes are potent activators of blood coagulation through the generation of MTF, which was recently implicated in the aetiology of acute coronary ischaemic syndromes.
\end{abstract}

Methods-MTF expression and adhesion molecules were measured in whole blood using immunofluorescence of monocytes labelled with anti-tissue factor antibody and CD11b and c by flow cytometry. PTf1+2 and $L p(a)$ lipoprotein in plasma were measured by enzyme linked immunosorbent assay (ELISA).

Patients-70 patients with CRF without documented coronary artery disease (30 patients with CRF undialysed, 20 patients undergoing chronic ambulatory peritoneal dialysis (CAPD), and 20 undergoing haemodialysis (HD)), together with 20

Results-The (mean (SD)) increased MTF of CRF (48.0 (29) $v 33.3$ (7.2) mesf unit/100 monocytes in controls, $p=0.04$ ) was more pronounced in patients undergoing dialysis (HD $73.1(32.8)(\mathrm{p}<0.003)$ and CAPD 62.8 (28.9) mesf unit/100 monocytes, $p<0.04)$. MTF activity showed a positive correlation (p < 0.003 ) but not with $\mathrm{Lp}$ (a) lipoprotein. Lp(a) lipoprotein was significantly increased in both dialysis groups compared with controls $(p<0.005)$ and non-dialysis CRF groups $(p<0.02)$. Monocyte adhesion molecule (CD11b) was significantly higher in all three CRF groups than in the controls

Conclusion-This study has demonstrated a hypercoagulable state in patients with CRF. This was especially pronounced in the dialysis patients. These findings provide a possible explanation for the increased cardiovascular and cere- brovascular morbidity and mortality in these patients.

(Heart 1999;81:134-140)

Keywords: chronic renal failure; haemodialysis; continuous ambulatory dialysis; monocyte tissue factor; monocyte adhesion molecules; prothrombin; $\mathrm{Lp}$ (a) lipoprotein

Recent advances in therapy of patients with chronic renal failure (CRF) have been associated with improved survival and enhanced quality of life. Nevertheless, life expectancy is still considerably reduced. The dominant cause of this increased mortality is accelerated atherosclerosis ${ }^{1}$ leading to cardiovascular death. ${ }^{2}$ Many factors contribute to this premature atherosclerosis, and it is becoming apparent that lipoprotein abnormalities are closely associated with increased atherosclerosis risk and correlate well with cardiovascular mortality. ${ }^{3}$

Ritz et al noted the relative risk of fatal myocardial infarction to be 9-170-fold greater in dialysed uraemic patients than in the general population. ${ }^{4}$ Samples from the renal and internal iliac arteries of uraemic individuals have shown unexpectedly advanced atherosclerosis and vascular aging compared with vessels from control populations. ${ }^{56}$

Acute myocardial infarction and cardiac death in the general population are associated with occlusive coronary thrombosis, ${ }^{78}$ and it is probable that the enhanced thrombogenesis plays an important pathogenic role. ${ }^{9}$ Indeed, several large epidemiological studies have shown increased concentrations of clotting factors VII, VIII, and fibrinogen to be independent risk factors for coronary artery disease. ${ }^{910}$

Monocytes (mononuclear white blood cells) are believed to play a key role in the development of the fatty streak, the earliest stage of atherosclerosis. ${ }^{11-13}$ Leucocyte endothelial adhesion is important for experimentally induced atherosclerosis, and is abnormal in patients with hyperlipidaemia. ${ }^{14}$ Monocyte adhesion molecule expression (mediated via integrin receptors) is increased in the coronary sinus blood of patients with unstable angina ${ }^{15}$; hence, the expression of monocyte adhesion molecules may be important in the pathogenesis of both acute and chronic phases of ischaemic heart disease.

Monocytes are known to exhibit pronounced procoagulant activity (PCA) in vitro when stimulated by endotoxin, ${ }^{16}$ tumour necrosis factor, ${ }^{17}$ and a variety of other immunological and inflammatory substances. ${ }^{18-21}$ Similar PCA normal controls, were studied. with both PTf1+2 and serum creatinine $(\mathbf{p}=0.006)$.

Department of
Cardiological
Sciences, St George's
Hospital Medical
School, Cranmer
Terrace, London
SW17 0RE, UK
N M Al-Saady
E W Leatham
S Gupta
C A Seymour
Department of Renal
Medicine, St George's
Hospital Medical
School, London
SW17 0RE, UK
J B Eastwood
Department of Renal
Medicine, St Helier
Hospital, Carshalton,
Surrey SM5 1AA, UK
J T C Kwan
Correspondence to:
Dr Al-Saady.
email: nalsaady@sghms.ac.uk
Accepted for publication
16 September 1998

Department of
Cardiological
Sciences, St George's
Hospital Medical
School, Cranmer
Terrace, London
SW17 0RE, UK
N M Al-Saady
E W Leatham
S Gupta
C A Seymour
Department of Renal
Medicine, St George's
Hospital Medical
School, London
SW17 0RE, UK
J B Eastwood
Department of Renal
Medicine, St Helier
Hospital, Carshalton,
Surrey SM5 1AA, UK
J T C Kwan
Correspondence to:
Dr Al-Saady.
email: nalsaady@sghms.ac.uk
Accepted for publication
16 September 1998 
has been described in monocytes isolated from animals injected with endotoxin ${ }^{22}$ and in patients presenting with various medical disorders associated with hypercoagulability. ${ }^{19} 23-25$ Recently monocytes from patients with unstable angina and myocardial infarction have been shown to have enhanced PCA and to correlate with markers of thrombin production. ${ }^{26-28}$ Furthermore, macrophages removed from atherosclerotic plaques displayed similar properties in vitro. $^{29}{ }^{30}$ It is therefore clear that monocyte PCA could be an important process in the aetiology of ischaemic heart disease. Evidence suggests that monocyte PCA is mediated by expression of a $47 \mathrm{kDa}$ integral membrane glycoprotein (tissue factor (TF)) on the cell surface. ${ }^{31}{ }^{32}$ This glycoprotein binds to coagulation factor VIIa, initiating both intrinsic and extrinsic pathways of the coagulation cascade. ${ }^{33} 34$

Another risk factor for increased atherogenesis is $\mathrm{Lp}$ (a) lipoprotein, which also enhances PCA of peripheral blood mononuclear cells in vitro. $^{35}$ There is clinical evidence of an association between high $\mathrm{Lp}$ (a) lipoprotein concentrations and premature cardiovascular disease. ${ }^{36}$ This association may also hold for patients with CRF, and we have shown in a pilot study that $\mathrm{Lp}$ (a) lipoprotein concentrations are significantly higher in chronic ambulatory peritoneal dialysis (CAPD) patients than in CRF patients. ${ }^{37}$

It is clear from the above that atherosclerosis development and enhanced thrombogenesis are important aetiological factors in the development of cardiovascular morbidity. As patients with CRF have such increased morbidity and mortality from cardiovascular and cerebrovascular events, it is clearly of interest to know if these factors operate in these patients. Our study provides evidence on the two pathogenic mechanisms, namely the development of atherosclerosis and the thrombogenic state.

\section{Patients and methods}

PATIENTS

Seventy patients with CRF-30 undialysed, 20 on CAPD, and 20 on haemodialysis (HD)were studied. The CRF patients were recruited consecutively and had serum creatinine concentrations of $150-600 \mu \mathrm{mol} / 1$. The CAPD and HD patients had been on dialysis for more than six months. They had not received heparin for at least 24 hours before blood sampling. Patients with malignancy, infection, existing known heart disease (angina or myocardial infarction), and diabetes mellitus were excluded from the study.

Twenty control subjects in good health, normolipidaemic, and receiving no drugs were selected from consecutive patients attending the outpatients' phlebotomy room for "screening" blood tests arranged by general practitioners.

SAMPLE COLLECTION

A venous sample was collected from each patient at between 08:00 and 10:00. The blood $(2 \mathrm{ml})$ was drawn into a prechilled EDTA Vacutainer and kept on melting ice until analysed.
MEASUREMENT OF MONOCYTE TISSUE FACTOR EXPRESSION

A $100 \mu$ volume of whole blood was incubated with $2 \mu \mathrm{g}$ of rabbit antihuman $\mathrm{TF}$ and anti-CD $11 b$ and $c$ antibodies (MoAb) for 30 minutes at $4^{\circ} \mathrm{C}$. This rabbit antihuman antibody has been shown previously to have high specificity for human $\mathrm{TF}$ in western blot experiments, and blocks the functional activity of TF in procoagulant assays.

Red cells were lysed with Q prep solution (Coulter Corporation, Luton, UK), washed twice in chilled phosphate buffered saline, and then incubated with $1 \%$ paraformaldehyde before flow cytometric analysis.

Non-specific binding of antibodies was assessed for primary and secondary antibodies, using control antibodies (rabbit antichicken and swine antirabbit antibodies, respectively). These controls allowed determination of an appropriate threshold of surface fluorescence on unstimulated cells from normal subjects, above which only low levels $(<2.5 \%)$ of non-specific binding occurred.

\section{FLOW CYTOMETRY}

A Becton Dickinson flow cytometer (Facscan, Becton Dickinson, Mountain View, California, USA) was used to measure monocyte TF (MTF) expression. Leucocytes were gated on forward and side scatter. Pilot experiments showed the monocyte population to be CD14 (Coulter) positive $(92(5 \%))$. Leucocyte surface fluorescence was measured using 10000 cells for each sample.

After determination of $\mathrm{TF}$ expression in normal subjects, we set a threshold value of $2.5 \% \mathrm{TF}$ positive cells, based on measurement of fluorescent activity without TF in standard samples. The flow cytometer was calibrated each day with calibration beads (CMPC, Hato Rey, Puerto Rico), which enabled the threshold for the detection of MTF to be standardised.

Lp(a) LIPOPROTEIN

$\mathrm{Lp}$ (a) lipoprotein concentration was measured using rate nephelometry in a Beckman Array 360CE. Rabbit antiserum (Dako Ltd, Cambridge, UK) was diluted 1 in 3 in buffer (Beckman buffer). Lp(a) lipoprotein calibrant (Immuno Ltd, Kent, UK) and samples were diluted 1 in 6 in apodiluent (Beckman apolipoprotein diluent) before analysis.

\section{LIPID PROFILE}

A standard lipid profile (total cholesterol, triglyceride, high density lipoprotein (HDL) cholesterol) was measured in the routine clinical biochemistry laboratory. Cholesterol and triglyceride were measured by enzymatic methods on the DAX 72 (cholesterol: method SM4 $1139 \mathrm{M} 90$; and triglyceride: method SM4 1148M90). HDL cholesterol was assayed after dextran sulphate/magnesium chloride precipitation of low density lipoprotein (LDL) cholesterol followed by cholesterol analysis of the supernatant on a 12 Monarch centrifuge analyser. LDL cholesterol was determined by the Friedwald calculation. 
Table 1 Mean (SD) lipid profiles in non-dialysed/dialysed patients with chronic renal failure and healthy controls

\begin{tabular}{lllll}
\hline & Normal controls & Chronic renal failure & CAPD & Haemodialysis \\
\hline Total cholesterol $(\mathrm{mmol} / \mathrm{l})$ & $4.95(0.9)(\mathrm{n}=20)$ & $5.93^{\star}(1.5)(\mathrm{n}=25)$ & $5.22(1.5)(\mathrm{n}=19)$ & $5.42(0.9)(\mathrm{n}=15)$ \\
Triglyceride $(\mathrm{mmol} / \mathrm{l})$ & $1.02(0.4)(\mathrm{n}=20)$ & $2.0^{\star}(1.0)(\mathrm{n}=25)$ & $2.17(1.6)(\mathrm{n}=19)$ & $1.91(1.0)(\mathrm{n}=15)$ \\
HDL cholesterol $(\mathrm{mmol} / \mathrm{l})$ & $1.47(0.4)(\mathrm{n}=20)$ & $1.13^{\star}(0.05)(\mathrm{n}=23)$ & $0.9^{\star}(0.3)(\mathrm{n}=12)$ & $1.19^{\star}(0.4)(\mathrm{n}=11)$ \\
LDL cholesterol $(\mathrm{mmol} / \mathrm{l})$ & $3.0(0.8)(\mathrm{n}=20)$ & $3.81^{\star}(1.0)(\mathrm{n}=23)$ & $3.45^{\star}(1.2)(\mathrm{n}=12)$ & $3.49^{\star}(0.7)(\mathrm{n}=11)$ \\
\hline
\end{tabular}

${ }^{\star} \mathrm{p}<0.05$.

CAPD, chronic ambulatory peritoneal dialysis; HDL, high density lipoprotein; LDL, low desnity lipoprotein.

STATISTICAL ANALYSIS

MTF comparisons between patients group and normal controls were made using the Kruskal-Wallis test for multiple group data and the $t$ test. Except for the non-parametric analysis of variance test for a difference between groups (Kruskal-Wallis) which was one tailed, all tests were two tailed; $p<0.05$ was considered significant. Multiple regression for MTF and prothrombin fragments $1+2(\mathrm{PTf} 1+2)$ was used for the differences in age and sex between patients and normal controls. Because the distribution of $\mathrm{Lp}$ (a) lipoprotein data was highly skewed, results were expressed as median and range and non-parametric analysis using Mann-Whitney U test was carried out to test the significance between the groups. For the lipid profile, a mean difference was tested using the unpaired $t$ test. Pearson correlation coefficients for $\mathrm{Lp}(\mathrm{a})$ lipoprotein, C reactive protein, and serum creatinine were also tested.

\section{Results}

The results of the lipid profiles are presented in table 1. Patients with CRF (undialysed) showed significantly higher concentrations of total cholesterol, triglycerides, and LDL cholesterol, and lower concentrations of HDL cholesterol, compared with the controls. CAPD and HD patients showed a similar trend but concentrations were only significantly different from controls for triglycerides and HDL cholesterol.

\section{ACUTE PHASE PROTEIN}

There were no significant differences in C reactive protein, $\alpha_{1}$ antitrypsin, and haptoglobin between the groups.

\section{MONOCYTE TISSUE FACTOR EXPRESSION}

Figure 1 shows representative histograms of monocyte surface MTF expression in one patient and one normal control. Increased MTF expression was observed in the dialysis and non-dialysis groups compared with normal controls (fig 2). Monocyte MTF expression (mesf unit/100 monocytes) was significantly raised in patients with CRF compared with controls (mean (SD)) (48 (29) v 33 (7.2); $\mathrm{p}=0.04)$. Furthermore, MTF expression was particularly high in those undergoing $\mathrm{HD}$ and CAPD (73.1 (32.8), $\mathrm{p}=0.003$, and 62.8 (28.9), $\mathrm{p}=0.04$, respectively), with no significant difference between the two dialysis groups (fig 2). The percentage of monocytes which showed expression of MTF was significantly higher in the dialysis and non-dialysis groups ( $51 \%$ and $43 \%$, respectively) compared with the controls $(18 \%, \mathrm{p}=0.013)$.

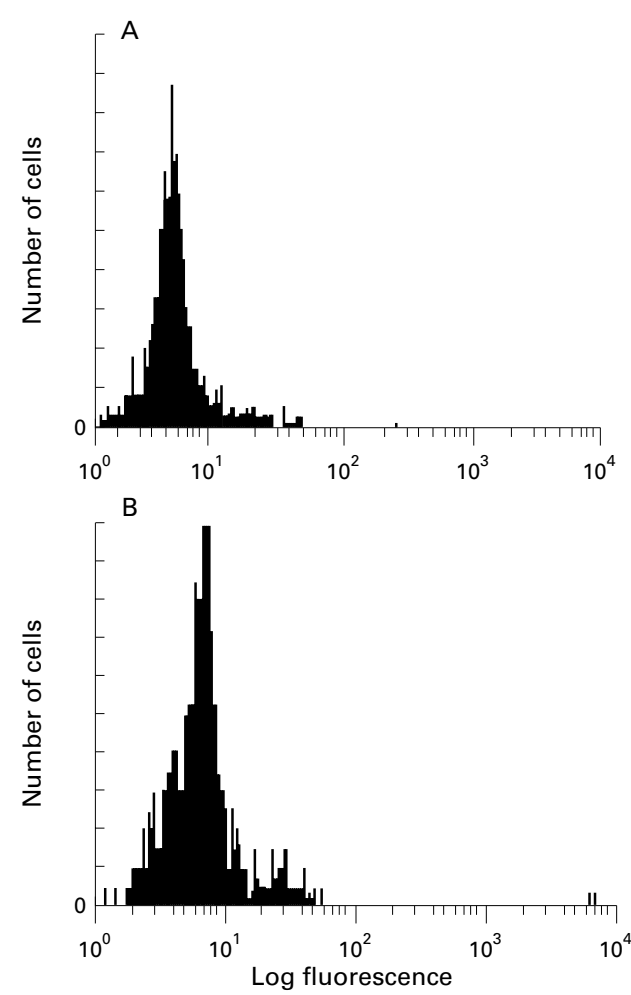

Figure 1 Histograms of fluorescence intensity (log scale). (A) Normal control. (B) Chronic renal failure patient.

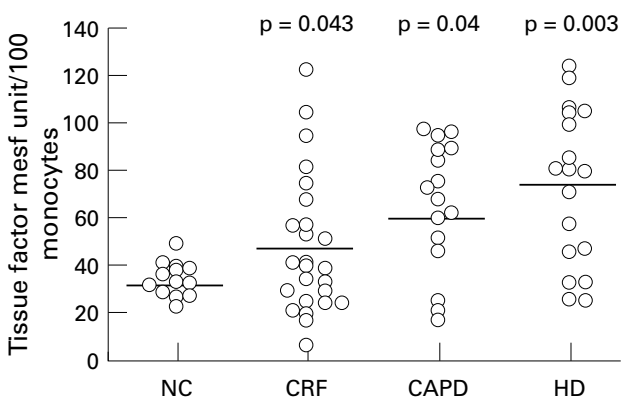

Figure 2 Monocyte tissue factor (MTF) expression in normal controls (NC) and chronic renal failure (CRF) patients. Data show individual's mean. $p$ values represent comparison with NC. CAPD, chronic ambulatory peritoneal dialysis; $H D$, haemodialysis.

Multiple regression model for MTF showed that the difference between patients and normal controls was 20.5 mesf unit/100 monocytes (95\% confidence interval (CI) 2.2 to $35.7, \mathrm{p}<0.03)$ after adjustment for age.

PROTHROMBIN FRAGMENTS $1+2$

PTf1+2 were significantly higher in the nondialysis CRF (1.7 (0.6) nmol/l) and dialysis groups (HD 3.2 (1.5) nmol/l, CAPD 2.3 $(0.8) \mathrm{nmol} / \mathrm{l})$ than in controls $(0.86$ (0.3) nmol/1, p < 0.001), with no significant difference between the two dialysis groups (fig 


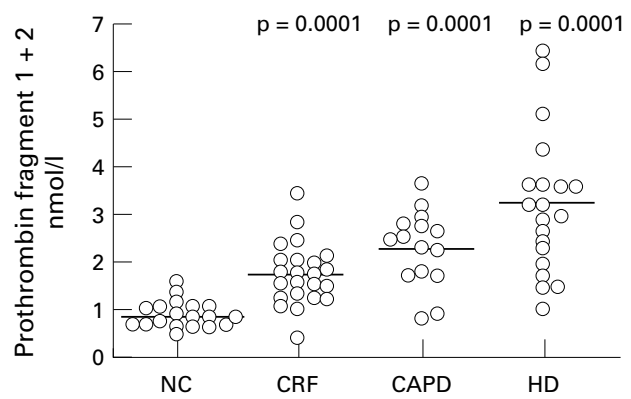

Figure 3 Prothrombin fragments $1+2(P T f 1+2)$ in normal controls (NC) and chronic renal failure (CRF) patients. Data show individual's mean. p values represent comparison with $N C$.

$3)$. There was a positive correlation between MTF expression and PTf $1+2(\mathrm{p}<0.004)$.

The multiple regression model for PTf $1+2$ showed that the difference between patients and normal controls after adjustment for age was $1.39 \mathrm{nmol} / 1 \quad(95 \%$ CI 0.8 to 1.88 , $\mathrm{p}=0.0001)$.

It was not possible to differentiate the effects of underlying renal disease on MTF or PTf $1+2$ because of the wide variation in the causes of renal failure. However, both MTF and PTf1+2 showed significant correlations with serum creatinine in the undialysed CRF patients ( $\mathrm{p}=0.0001$ and 0.0001 , respectively). This suggests that the severity of the renal failure is positively associated with influence on MTF and PTf1+2.

ADHESION MOLECULES

Adhesion molecule CD11b (mesf unit/100 monocytes) was significantly higher $(\mathrm{p}=0.006)$ in dialysis and non-dialysis groups compared with normal controls (mean (SD): for normal controls 10.2 (3.6), for undialysed CRF patients 16.5 (9.2), for CAPD patients 18.4 (12), and for HD patients 21.1 (8.5)) (fig 4). CD11c, although showing a similar trend to CD11b, did not reach statistical significance. CD11c (mesf unit/100 monocytes) in normal controls was 8.6 (3.1), while in undialysed CRF patients it was 11.8 (8), in CAPD patients it was 13.4 (10.8), and in HD patients it was 12.0 (4).

CD11b showed a positive correlation with CD11c $(p=0.0001)$ and serum creatinine $(p=0.0001)$. Both MTF and PTf $1+2$ showed a positive correlation with CD11b ( $\mathrm{p}=0.003$, $p=0.0001$, respectively).

Lp(a) LIPOPROTEIN

$\mathrm{Lp}$ (a) lipoprotein serum concentrations were significantly higher in dialysis and non-dialysis patients than in controls ( $\mathrm{p}<0.003)$ : median (range) for normal controls 6.2 (5.0-41.5) $\mathrm{mg} / \mathrm{dl}$, for undialysed CRF patients 16.2 (5.0192.5) $\mathrm{mg} / \mathrm{dl}$, for CAPD patients 47.5 (5.0153.2) $\mathrm{mg} / \mathrm{dl}$, and for HD patients 42.6 (5.0-160.0) $\mathrm{mg} / \mathrm{dl}$ (fig 5). $\mathrm{Lp}(\mathrm{a})$ lipoprotein showed a positive correlation only with serum creatinine $(\mathrm{p}=0.01)$; no significant correlation was found between $\operatorname{Lp}(\mathrm{a})$ lipoprotein and MTF or PTf1+2.

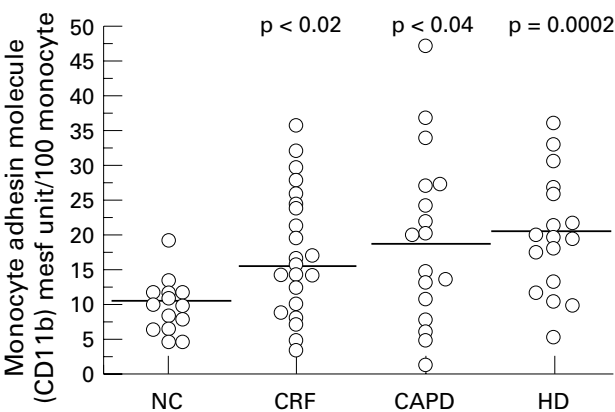

Figure 4 Monocyte adhesion molecules in normal controls (NC) and chronic renal failure (CRF) patients. Data show individual's mean. $p$ values represent comparison with NC.

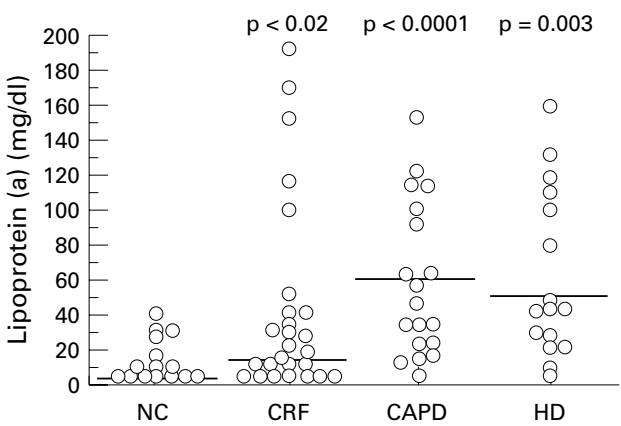

Figure 5 LP (a) lipoprotein in normal controls (NC) and chronic renal failure (CRF) patients. Data shows

individual's median. $p$ values represent comparison with NC.

\section{Discussion}

In this study we show for the first time that MTF expression is increased in dialysis (CAPD and HD) and non-dialysis CRF patients compared with healthy control subjects, with the highest values being in the dialysis groups. Another new finding is that increased monocyte MTF expression is associated with a significantly raised serum concentration of PTf1+2 (an index of thrombin generation). There was a fourfold increase in PTf $1+2$ in the HD group, a threefold increase in the CAPD group, and a twofold increase in the non-dialysis group compared with the control group. Furthermore, monocyte integrin (adhesion molecule CD11b) expression was significantly increased in the non-dialysis and dialysis groups compared with the control group.

Renal abnormalities may cause both a bleeding diathesis and a hypercoagulable state. $^{38} 39$ In patients on regular HD, haemostatic abnormalities include an increase of coagulation factors (fibrinogen and FVIIc), ${ }^{40} 41$ low concentrations of coagulation inhibitors (protein C, antithrombin III, and heparin cofactor II), ${ }^{38}{ }^{41-44}$ and an increase of molecular markers of coagulation activation (thrombinantithrombin II, PTf $1+2$, plasmin $\alpha_{2}$-plasmin inhibitor complex, and D-dimer). ${ }^{40}{ }^{41}$ Raised plasma concentrations of thrombomodulin and von Willebrand factor have also been reported, ${ }^{41-47}$ perhaps indicating endothelial cell injury in dialysis patients. These abnormalities, in addition to lipid abnormalities, ${ }^{48}$ may explain in part the high incidence of cardiovascular death in chronic HD patients. In the present study, we found that MTF 
expression by monocytes correlated positively with thrombin generation (indicated by measured PTf1+2), the combination of which would be a potential risk for cardiovascular disease. This new evidence indicates that patients on regular dialysis have a hypercoagulable state.

MTF expression was measured using flow cytometry. This technique is used to measure immunofluorescence of cells labelled with appropriate antibodies and is able to detect specific cell surface receptors as markers. The technique has been accurately used for the assessment of leucocyte intern (adhesion molecules) and to study monocyte MTF expression. $^{28}{ }^{49}$ Luther $^{49}$ showed that MTF expression, determined cytometrically, had significant correlation with in vitro PCA. Furthermore, direct measurement of monocyte MTF with this method is more sensitive than PCA and is less likely to be influenced by PCA inhibitors. Flow cytometric measurement of monocyte MTF expression is usually carried out using Ficoll separated monocytes. ${ }^{49} \mathrm{Al}$ though a whole blood technique ${ }^{50}$ is now common practice for labelling blood cells with other antibodies, we were the first to describe a whole blood method for assessing monocyte MTF expression in coronary artery disease patients in a previous study, ${ }^{28}$ and in patients with CRF in the present study (fig 1). This method has the advantage of reducing the time taken to label monocytes. Furthermore the rapid incubation at $4^{\circ} \mathrm{C}$ reduces the chance of sample contamination with endotoxin, which might cause an artefactual increase in MTF expression.

Neri Serneri and colleagues ${ }^{26}$ have shown that separated mononuclear cells show increased procoagulant or "TF-like" activity in cultured monocytes from patients with unstable angina compared with convalescent and normal control samples. One other report of increased monocyte related PCA in unstable angina has been published in abstract form. ${ }^{27}$ Our previous ${ }^{28}$ and present studies indicate that such mononuclear cell procoagulant effects are mediated, in part, by $\mathrm{TF}$ expressed on monocytes.

$\mathrm{TF}$, an integral membrane protein located on the surfaces of certain cell types, is generally held to be the physiological trigger of coagulation in normal haemostasis. It activates both intrinsic and extrinsic coagulation pathways. Thus expression of MTF on circulating monocytes is likely to result in an enhanced systemic coagulant state, which may have a role in atherothrombosis. Monocytes are the only circulating blood cells capable of expressing MTF. Furthermore, as monocyte adhesion, migration, and transformation into tissue macrophages is known to occur at the site of atherosclerotic plaque, focal production of TF may explain the propensity for thrombosis at the site of an atheromatous plaque. CRF monocytes may therefore provide a useful model for further investigation of the increased atherogenesis and thrombosis which occurs in $\mathrm{CRF}$ despite reduction in urea and other "uraemic" toxins by treatment.
There are only two published studies of MTF in CRF. ${ }^{52} 53$ Unlike our study, both groups measured plasma $\mathrm{TF}$ rather than monocyte MTF expression. Like us, however, they found increased plasma TF in the patients with CRF and even higher concentrations in their HD patients. Our study is likely to be more clinically relevant, in that we have measured monocyte MTF rather than plasma $\mathrm{TF}$ expression in the cell intimately involved in atherogenesis. Furthermore, unlike these two studies, ${ }^{52}{ }^{53}$ we have measured the impact of the increased MTF activity on thrombogenicity $(\mathrm{PTf} 1+2)$ and found that it correlates well $(\mathrm{p}<0.003)$.

Conversely Koyama et al reported that plasma TF concentrations were increased in uraemic patients on chronic dialysis, while remaining within the normal range in nondialysis uraemic patients. ${ }^{52}$ Differences between these two studies may be explained in part by the different antibodies used in the enzyme linked immunosorbent assay (ELISA) systems.

Kario et al reported in a separate study that plasma TF pathway inhibitor (TFPI) activity was also considerably increased in uraemic patients. ${ }^{54}$ TFPI is a powerful inhibitor of the factor VIIa/TF complex in the presence of factor $\mathrm{Xa}$, as well as being a direct inhibitor of FXa. ${ }^{556}$ The high concentration of TFPI in their study might thus act as a balance to the increase of FVIIa in uraemia. However, in our study PTf $1+2$ was used as an index of thrombin generation rather than FVIIa or TFPI. PTf $1+2$ plasma concentrations were considerably increased in dialysis and nondialysis groups, indicating that monocyte MTF expression was not balanced by the generation of TFPI.

Monocyte MTF expression can be induced in vitro by a variety of stimuli including soluble immune complexes, ${ }^{57}$ lymphokines, ${ }^{58}$ lectins, ${ }^{59}$ endotoxins, ${ }^{49}$ viruses, ${ }^{60}$ and chemically modified LDL. ${ }^{61}$ The cause of increased monocyte surface MTF and integrin expression in patients with CRF is currently uncertain. One possible explanation is that they are an acute phase response to tissue damage. We think this is unlikely, as other components of this response (C reactive protein, $\alpha_{1}$ antitrypsin, and haptoglobin) were normal in our CRF patients. In our study monocyte MTF and integrin expression as well as PTf1+2 and $\mathrm{Lp}$ (a) lipoprotein correlated positively with serum creatinine, which indicates that renal impairment itself may contribute to these raised concentrations.

Our findings similarly suggest that monocyte MTF expression may be less transient than is generally accepted. The increased expression in these patients together with thrombin generation indicates a hypercoagulable state in which monocytes may play a major role. Furthermore the increased expression of monocyte integrin might indicate a continuous or intermittent stimulation or trigger leading to their activation. Tissue damage and necrosis in the region of an atheromatous plaque may stimulate circulating monocytes and account 
for the increased expression of both adhesion molecules and MTF found in our study. Alternatively, or in addition, an increased monocyte MTF expression may precede acute coronary syndromes and may predispose to their development.

The patients in our study had no manifestations of ischaemic heart disease. Furthermore not all patients showed an increased percentage of MTF positive monocytes. Almost half the monocytes showed an increased expression of MTF compared with only $18 \%$ in the healthy control subjects. This finding does not invalidate our hypothesis that monocytes initiate thrombosis, as MTF expression is only one of several mechanisms by which these cells may induce thrombosis. Monocytes have been shown to produce several constituents of the clotting cascade, including factors V, VII, VIII, Mac-1 dependent factor $\mathrm{X}$, and prothrombinase. ${ }^{62} 63$

The changes in $\mathrm{Lp}$ (a) lipoprotein, which we have noted in this study and previously, ${ }^{37}$ although not showing any correlation with monocyte expression of MTF or integrin, would also suggest an independent thrombogenic role. This, together with the finding of dyslipidaemia (an increase in the atherogenic lipoproteins, LDL cholesterol and triglyceride, and a decrease in the protective lipoprotein, HDL cholesterol) in these patients are further evidence of an increased risk of atherosclerosis and its acceleration.

Our study did not look at markers of endothelial dysfunction/injury, such as thrombomodulin and von Willebrand factor, to see if they had any relation to our findings. Investigation of monocyte MTF, integrin, and PTf $1+2$ in CRF patients with ischaemic heart disease will be needed in further studies. However, this study demonstrates that CRF monocytes, because of the increased expression of adhesion molecules, are a good model for studying the activity and role of monocyte MTF expression as a coronary artery disease risk factor.

In summary, this study shows that circulating monocytes from CRF patients exhibit increased expression of MTF and integrin. The positive correlation with thrombin generation suggests that their blood is hypercoagulable. Furthermore, these patients have increased serum concentrations of atherogenic lipoproteins, especially $\mathrm{Lp}$ (a) lipoprotein, which puts them at an increased risk of accelerated atherosclerosis/increased thrombogenicity. These abnormalities are of particular interest because they persist despite treatment, and are even more pronounced in the dialysed patients. Clearly any specific therapy for preventing atherosclerosis in these patients needs to be directed not only at the hypercoagulable state but also at monocyte adhesion.

We would like to thank Dr Jan Poloniecki for his invaluable expert advice in planning the study, statistical analysing and reading the manuscript. This work is fully supported by a British Heart Foundation project grant (BHF-PG94153).

1 Lindner A, Charra B, Sherrand D, et al. Accelerated atherosclerosis in prolonged maintenance hemodialysis. $N$ Engl $\mathcal{F}$ Med 1974;290:698-701.
2 Haire HM, Sherrad DJ, Scardapane D, et al. Smoking, hypertension and mortality in a maintenance dialysis hypertension and mortality in a mainten

population. Cardiovasc Med 1978;7:1163-8.
3 Hahn R, Oette K, Mondorf H, et al. Analysis of cardiovascular risk factors in chronic hemodialysis patients with special attention to the hyperlipoproteinemias. Atherosclerosis 1983;48:279-88.

4 Ritz E, Augustin J, Bommer J, et al. Should hyperlipidaemia of renal failure be treated? Kidney Int 1985;28:584-7.

5 Vincenti F, Amend WJ, Abele J, et al. The role of hypertension in hemodialysis associated atherosclerosis. Am $\mathcal{7}$ Med 1980;68:363-9.

6 Ibels LS, Alfrey AC, Huffer WE, et al. Arterial calcification and pathology in uremic patients undergoing dialysis. $A m \mathcal{F}$ Med 1979;66:790-6.

7 Schwartz CJ. Thrombosis in the pathogenesis of sudden cardiac death and myocardial infarction. In: Oates AJ, ed. Prostaglandins and cardiovascular system. New York: Raven Press, 1982:1-14.

8 Davies MJ, Thomas A. Thrombosis and acute coronaryartery lesions in sudden cardiac ischaemic death. $\mathrm{N} \mathrm{Engl} \mathrm{f}$ Med 1984;310:1137-40.

9 Heinrich J, Balleisen L, Schulte H, et al. Fibrinogen and factor VII in the prediction of coronary risk. Results from the PROCAM study in healthy men. Arterioscler Thromb 1993; 14:54-9.

10 Meade TW, Imerson J, Stirling Y. Effects of changes in smoking and other characteristics on clotting factors and the risk of ischaemic heart disease. Lancet 1987;ii:986-8.

11 Gerrity RG, Naito HK, Richardson $M$, et al. Dietaryinduced atherogenesis in swine. I. Morphology of the intima in pre-lesion stages. Am f Pathol 1979;95:775-92.

12 Aqel NM, Ball RY, Waldman $\mathrm{H}$, et al. Monocytic origin of foam cells in human atherosclerotic plaques. Arteriosclerosis 1984;53:265-71.

13 Rosenfeld ME, Tsukada T, Gown AM, et al. Fatty streak initiation in Wantanabe heritable hyperlipidemic and comparably hypercholesterolemic fat-fed rabits. Atherosclerosis 1987;7:9-23.

14 Bath P, Gladwin A, Martin J. Human monocyte characteristics are altered in hypercholesterolaemia. Atherosclerosis 1991;90:175-81.

15 Mazzone A, De Servi S, Ricevuti G, et al. Increased expression of neutrophil and monocyte adhesion molecule expression molecules in unstable coronary artery disease. Circulation 1993;88:358-63.

16 Rivers R, Hathaway W, Weston W. The endotoxin-induced coagulant activity of human monocytes. $\mathrm{Br} \mathcal{F}$ Haematol 1975;30:311-16.

17 Conkling P, Greenberg C, Weinberg J. Tumor necrosis factor induces tissue-factor-like activity in human leukaemia cell line U937 and peripheral blood monocytes. Blood 1988;72:128-33.

18 Drake TA,Hannani K, Fei $\mathrm{H}$, et al. Minimal oxidised low-density lipoprotein induces tissue factor expression in cultured human endothelial cells. Am f Pathol 1991;38: 601-7.

19 Lyberg T, Prydz N, Baklein K, et al. Effects of immune complex-containing sera from patients with rheumatic diseases on thromboplastin activity of monocytes. Thromb Res 1982;25:193-202.

20 Prydz H, Lyberg T, Deterix P, et al. In vitro stimulation of tissue thromboplastin (factor III) activity in human monocytes by immune compexes and lectins. Thromb Res 1979; 15:465-74.

21 Kornberg A, Catane R, Peller S, et al. Tuftsin induces tissue factor-like activity in human mononuclear cells and monocytic cell lines. Blood 1990;76:814-19.

22 Niemetz J. Coagulant activity of leucocytes. Tissue factor activity. $\mathcal{F}$ Clin Invest 1972;51:307-13.

23 Rivers RP, Cattermole H E , Wright I. The expression of surface tissue factor apoprotein by blood monocytes in the course of infections in early infancy. Pediatr Res 1992;31: 567-73.

24 Osterud B, Flaegstad T. Increased tissue thrombosplastin activity in monocytes of patients with meningococcal infection: related to an unfavourable prognosis. Throm Haemost 1983;49:5-7.

25 Lorenzet R, Peri G, Locati D, et al. Generation of procoagulant activity by mononuclear phagocytes: a possible mechanism contributing to blood clotting activation with malignant tissues. Blood 1983;62:271-3.

26 Neri Serneri G, Abbate R, Gori A, et al. Transient intermittent lymphocyte activation is responsible for the instability of unstable angina. Circulation 1992; 86:790-7.

27 Agraou B, Jude B, McFadden E, et al. Increase in monocyte procoagulant activity (PCA) in unstable angina (UA), procoagulant activity (PCA) in unstable angina (UA),
compared to stable angina and coronary angioplasty compared to stable angina and coronary

28 Leatham EW, Bath PMW, Tooze JA, et al. Increased monocyte tissue factor expression in coronary disease. Br Heart $\mathcal{F}$ 1995;73:10-13.

29 Tipping PG, Malliaros J, Holdsworth SR. Procoagulant activity expression by macrophages from atheromatous vascular plaques. Atherosclerosis 1989;79:237-43.

30 Wilcox JN, Smith K, Schwartz S, et al. Localization of tissue factor in normal vessel wall and in the atherosclerotic plaque. Proc Nat Acad Sci 1989;86:2839-43.

31 Rickles FR, Edwards RL, Levin JB, et al. Tissue factor generation by human mononuclear cells: effects of endotoxin and dissociation of tissue factor generation from mitogenic response. F Lab Clin Med 1977;89:792-803. 
32 Edwards RL, Rickles FR. The role of leucocytes in the activation of blood cosulation. Semin Hematol 1992;29:202 12 .

33 Nemerson Y. Tissue factor and hemostasis. Blood 1988;71 $1-8$

34 Rapaport SI, Mohan Rao L. Initiation and regulation of tissue-factor dependent blood coagulation. Arterioscleros Thromb 1990;12:1111-21.

35 Scwartz BS, Levy GA, Curtis LK, et al. Plasma lipoprotein induction and suppression of the generation of cellular procoagulant activity in vitro. $\mathcal{F}$ Clin Invest 1981;67:1650-8.

36 Dahlen GH, Guyton JR, Attar M, et al. Association of levels of lipoprotein (a), plasma lipids, and other lipoproteins with coronary artery disease documented by angiography. Circulation 1986;74:758-65.

37 Al-Saady NM, Davies S, Lunt R, et al. Raised plasma lipoprotein $\mathrm{Lp}(\mathrm{a})$ level is higher in patients undergoing continuous ambulatory dialysis compared to chronic renal failure. Clinical Biochemist May Focus 1994.

38 Eberst ME, Berkowitz LR Hemostasis in renal disease: pathophysiology and management. Am 7 Med 1994;96: pathophysic

39 Robinson G, Talbot S, Chitolie A, et al. Platelet von Willebrand factor and bleeding in chronic renal failure. $\mathcal{F}$ Nephrol 1995;8:41-22.

40 Kario K, Matsuo T, Yamada T, et al. Factor VII hyperactivity in chronic dialysis patients. Thromb Res 1992;67:10513.

41 Nakamura Y, Chida Y, Tomura S. Enhanced coagulationfibrinolysis in patients on regular hemodialysis treatment. Nephron 1991;58:201-4.

42 Sorensen PJ, Knudsen F, Nielsen AH, et al. Protein C assays in uremia. Thromb Res 1989;54:301-10.

43 Faioni EM, Franchi F, Krachmalnicoff A, et al. Low levels of anticoagulant activity of protein $\mathrm{C}$ in patients with chronic renal insufficiency: an inhibitor of protein $\mathrm{C}$ is present in uremic plasma. Thromb Haemost 1991;66:420-5.

44 Toulon P, Jacquot C, Capron L, et al. Anti-thrombin III and heparin cofactor II in patients with chronic renal failure heparin cofactor II in patients with chronic renal failure un

45 Takano S, Kimura S, Ohdama S, et al. Plasma thrombomodulin in health and diseases. Blood 1990;76:2024-9.

46 Turney JH, Woods HF, Fewell MR, et al. Factor VIII compex inuraemia and effects of haemodialysis. BMF 1981 282:1653-6.

47 Yamazaki M, Asakura $\mathrm{H}$, Sato $\mathrm{T}$, et al. Change in plasma levels of thrombomodulin during haemodialysis. Blood Coagul Fibrinolysis 1992;3:113-17.

48 Attman P-O, Alaupovic P. Lipid abnormalities in chronic renal insufficiency. Kidney Int 1991;39(suppl):S16-23.
49 Luther T, Fossel C, Hietschhold V, et al. Flow cytometric analysis of tissue factor (TF) expression on stimulated monocytes-comparison to procoagulant activity of monomonocytes-comparison to procoagulant

50 Caldwell CW, Taylor HM. A rapid, no-wash technique for mmunophenotypic analysis by flow-cytometry. Am f Clin Pathol 1985;86:600-7.

51 Withdrawn.

52 Koyama T, Nishida K, Ohdama S, et al. Determination of plasma tissue factor antigen and its clinical significance. $\mathrm{Br}$ f Haematol 1994;84:343-7.

53 Kario K, Matsuo T, Matsuo M, et al. Marked increased of activated factor VII in uraemic patients. Thromb Haemost 1995;73:763-7.

54 Kario K, Matsuo T, Yamada T, et al. Increased tissue factor pathway inhibitor levels in uraemic patients on regular haemodialysis. Thromb Haemost 1994;71:275-9.

55 Broze GJ Jr. The tissue factor pathway of coagulation: factor VII, tissue factor and tissue factor pathway inhibitor. In: Bloom AL, Forbes CD, Thomas DB, Tuddenham EGD, eds. Haemostasis and thrombosis. London: Churchill Livingstone, 1994:349-77.

56 Lindahl AK, Sandset PM, Abildgaard U. The present status of tissue factor pathway inhibitor. Blood Coagul Fibrinolysis 1992;3:439-49.

57 Rothberger H, Zimmerman TS, Spiegelberg HL, et al. Leukocyte procoagulant activity: enhancement of production in vitro by IgG and antigen-antibody complexes. $\mathcal{F}$ Clin Invest 1977;59:549-57.

58 Geczy CL, Hopper KE. A mechanism of migration inhibition in delayed-type hypersensitivity reactions. II. Lymphokines promote procoagulant activity of macrophages in vitro. F Immunol 1981;126:1059-65.

59 Prydz H, Lyberg T, Deteix P, et al. In vitro stimulation of tissue thromboplastin (factor III) activity in human monocytes by immune complexes and lectines. Thromb Res $1979 ; 15: 465-74$

60 Levy GA, Leibowitz JL, Edgington TS. Induction of monocyte procoagulant activity by murine hepatatis virus type 3 parallel disease susceptibility in mice. F Exp Med 1981;154: parallel disea 1150 .

61 Schuff-Werner P, Claus G, Armstron VW, et al. Enhanced procoagulant activity (PCA) of monocyte/macrophages after in vitro stimulation with chemically modifies LDL. Atherosclerosis 1989;78:109-12

62 Edwards RL, Rickles FR. The role of leukocytes in the activation of blood coagulation. Semin Hematol 1992;29:20212 .

63 Shands JW. Macrophages procoagulants. Haemostasis 1984; 14:3373-7. 